Article

\title{
Public Deliberation in Russia: Deliberative Quality, Rationality and Interactivity of the Online Media Discussions
}

\author{
Olga Filatova ${ }^{1, *}$, Yury Kabanov ${ }^{2,3}$ and Yuri Misnikov ${ }^{2}$ \\ ${ }^{1}$ Department of Public Relations in Politics and Public Administration, School of Journalism and Mass Communications, \\ St. Petersburg State University, 199004 St. Petersburg, Russia; E-Mail: o.filatova@spbu.ru \\ 2 eGovernment Center, ITMO University, 199034 St. Petersburg, Russia; E-Mail: yuri.misnikov@gmail.com \\ ${ }^{3}$ Department of Political Science, National Research University Higher School of Economics, 190068 St. Petersburg, Russia; \\ E-Mail: ykabanov@hse.ru \\ * Corresponding author
}

Submitted: 15 December 2018 | Accepted: 15 March 2019 | Published: 9 August 2019

\begin{abstract}
Deliberation research is now undergoing two emerging trends: deliberation is shifting from offline to online, as well as from an inherently democratic concept to the one applicable to less competitive regimes (He \& Warren, 2011). The goal of this article is to study the peculiarities of deliberative practices in hybrid regimes, taking online discourse on the Russian antisanctions policy as a case. We use the Habermasian concept of basic validity claims to assess deliberation quality through the lens of argumentation and interactivity. Our findings suggest that deliberative practices can exist in non-competitive contexts and non-institutionalized digital spaces, in the form of intersubjective solidarities resulting from the everyday political talk among ordinary citizens. Such deliberations can be counted as argumentative discourses, although in a special, casual way-unlike the procedural rule-based debates. Generally, as in established liberal democracies, deliberation in Russia tends to attract like-minded participants. While the argumentative quality does not seem to vary across the discussion threads sample, the level of deliberative interactivity is higher on pro-government media, accompanied with the higher level of incivility. On the other hand, discourses on independent media are distinctively against the government policy of food destruction. The democratic value of such deliberations is unclear and might depend on the political allegiance and ownership of the media. Though some discourses can be considered democratic, their impact on decision-making remains minimal, which is a key constraint of deliberation.
\end{abstract}

\section{Keywords}

argumentation; authoritarian deliberation; civility; deliberation; interactivity; internet discussions; media; online discourse; validity claims

\section{Issue}

This article is part of the issue "Public Discussion in Russian Social Media", edited by edited by Olessia Koltsova (Higher School of Economics, Russia) and Svetlana Bodrunova (St. Petersburg State University, Russia).

(C) 2019 by the authors; licensee Cogitatio (Lisbon, Portugal). This article is licensed under a Creative Commons Attribution 4.0 International License (CC BY).

\section{Introduction}

Since its emergence, deliberation research has been strongly associated with democracy as a goal of deliberation or at least an object of study. This democracy quest has been then extended online (Friess \& Eilders, 2015). Yet searching for deliberation in non-democratic contexts, derived from the Chinese experience of citizen engagement, is another emerging trend. The authoritarian deliberation theory (He \& Warren, 2011) has already gone online (Jiang, 2010) and beyond China (Romano, 2018; Toepfl, 2018), and, furthermore, from spaces created and totally controlled by governments to grassroot deliberation practices (He, Tang, \& Tamura, 2018, 
pp. 798-799; Medaglia \& Yang, 2017; Medaglia \& Zhu, 2017), which, however, remain underexplored due to the lack of context-related research. Hence, we aim at contributing to the authoritarian deliberation research by exploring the peculiarities, opportunities and constraints of deliberative practices in non-democracies.

Our study differs from the most in authoritarian deliberation research in several respects. First, we take the case of Russia, which has a different, hybrid modification of regime known as electoral authoritarianism (Gel'man, 2015), i.e., the one that has certain 'democratic' institutions and limited political pluralism. Such pluralism is still visible online, since the RuNet has been for a long time developing relatively freely (Soldatov \& Borogan, 2015). It allows us to assess and compare deliberation processes and outcomes depending on the relationship between the government and a certain outlet.

Secondly, we examine deliberative practices on several online discussion platforms among ordinary, politically non-organized citizens. In contrast to invited spaces (Kersting, 2013) controlled by governments, such discussions represent non-institutionalized (semi-) invented virtual public spaces-or rather 'third places' (Wright, 2012)-where members of the public engage in computer-mediated communications to discuss salient issues freely. Here we distinguish the media outlets themselves (that can be under direct or indirect government influence) from the online discussions they host (which are free from such control, as there is no evidence that such discussions are coerced or manipulated-there is no lack of criticism towards authorities on other issues in the past discussions as well). In this view, our aim is to better understand whether deliberation quality and outcomes would differ across online discussion platforms depending on the political affiliation of their host owners.

Thirdly, we choose one highly politically and morally sensitive issue, namely, the discussion of destroying Western food under embargo following the Russian counter-sanctions policy, to study such discussions from a deliberation perspective; the latter includes such features as civility, interactivity, argumentation and the prevailing positions towards the food destruction policy. In doing so, we start with the review of existing theories on deliberation and authoritarian deliberation, followed by the elaboration of research methodology, describing the deliberation standard, against which the discussion content was coded. Then we present the empirical case study. The article ends by demonstrating and discussing the research findings.

\section{Reconceptualizing Deliberation in the Internet Era}

\subsection{Democratic Value of Deliberation as Argumentative Reason}

As theorized by Jurgen Habermas, deliberation is a deeply democratic phenomenon within the (idealized) concept of the public sphere and participatory democracy (Bohman \& Rehg, 1997, p. XII; Habermas, 1992a). His theories of discourse ethics and communicative action decouple the Kantian notion of reason and will-formation from the subjective selves of individuals into the discursively (and collectively) constructed intersubjective solidarities formed during deliberation (Habermas, 1984, 1987, 2006). In this interpretation, deliberation broadens its meaning to include everyday communicative practices among ordinary citizens. Habermas calls such practices 'practical discourses' where citizens are engaged in truth-tracking moral discussions to understand others by making claims to validity (Habermas, 1992b, pp. 52, 103, 122). Habermas (1992a, p. 19) argues, for example, that:

Everyday communication makes possible a kind of understanding that is based on claims to validity and thus furnishes the only real alternative to exerting influence on one another in more or less coercive ways. The validity claims that we raise in conversationthat is, when we say something with convictiontranscend this specific conversational context, pointing to something beyond the spatiotemporal ambit of the occasion. Every agreement, whether produced for the first time or reaffirmed, is based on (controvertible) grounds of reason. Grounds have a special property: they force us into yes or no positions.

'Yes' and 'No' positions emerge when discourse participants make the basic claim to the validity of shared values, 'intersubjective' normative rightness (Habermas, 1987 , pp. 313-314, 1984, p. 52). Being aware of this way of reasoning encourages citizens to respond by validating such claims and displaying the reason behind 'Yes' and 'No' positions. Habermas (1984, p. 31) specifically argues that the theory of argumentation must be equipped with a more comprehensive concept of validity that is not restricted to validity in the sense of truth'. It is the hearer who ultimately decides which claims seem 'truthful' to be validated by agreement or disagreement on the basis of universal or group moral and ethical standards.

In the Habermasian tradition, deliberation is a participatory form of politically, morally, and ethically justified discourse when citizens voluntarily discuss politics in a casual manner to present competing perspectives through public reasoning instead of bargaining; the latter is typical for the pluralist democratic model (Bohman \& Rehg, 1997, pp. XII-XIII). They claim that decision-making should not result from the economics of the rationalchoice approach, but from public deliberation, from a communicatively constructed public will, so as democratic policies accommodate not only competing group interests, but also the commonly shared public values (Bohman, 1996; Elster, 1998). Gutmann and Thompson (2004), for example, define deliberative democracy as a 'need to justify decisions made by citizens and their representatives' through exchanging reasons among 'free 
and equal persons seeking fair terms of cooperation' (Gutmann \& Thompson, 2004, p. 3). However, Dryzek (2000) questions the view that deliberation should be associated with discussions that are (unnaturally) calm, reasoned, argumentative, whereas the genuine communication in democracy should include the real-life discursive processes that are intrinsically social, intersubjective invoking all kinds of 'unruly and contentious communications from the margin' (Dryzek, 2000, p. VI). Mutz (2006) and Gastil (2008) concur that the routine political conversations between neighbors, family members or coworkers are to be counted as the core deliberation practice in the common public sphere.

While some are skeptical that the Internet improves democratic deliberation (Sunstein, 2009), others (Coleman, 2017) believe that it is not about the Internet which just offers new opportunities for strengthening democracy, but it is rather our failure to benefit from such democratic opportunities. Even in democracy, citizens with similar political views develop unhealthy fragmentation and group polarization leading to the 'likeminded enclaves' and 'eventually to a polarized opinion climate in the whole society' (Strandberg, Himmelroos, \& Grönlund, 2019, p. 12). Jonsson and Åström (2014, p. 1) in their review of the online deliberation research acknowledge the belief that whilst the idealized version of 'pure deliberation' has not yet been realized online, it is an expanding field trying 'to re-link deliberative theory with empirical political science' in a hope to address these fears. We support a view that empirical evidence is still scarce to clarify more credibly the link between deliberation as a real-life practice and public politics well beyond governing practices of western liberal democracies.

\subsection{Authoritarian Deliberation: From Invented to (Semi-)Invited Spaces}

Although the media freedom subversion is a common trait of non-democracies, its intensity differs across regimes (Stier, 2015) and goes beyond total censorship to more liberated forms (Huang, Boranbay-Akan, \& Huang, 2019; Stafford, 2017), with a vast repertoire of control over officially independent outlets (Schedler, 2009). Such strategies can be found on the Internet as well, when filtering and censorship are masterfully combined with citizens' input and free discussion to ensure regime stability (Gunitsky, 2015). This observation is quite in line with the trend of making citizens' input a source of authoritarian stability (Gerschewski, 2013), including online participation (Åström, Karlsson, Linde, \& Pirannejad, 2012).

These tendencies give rise to the concept of authoritarian deliberation (He \& Warren, 2011) that combines deliberative governance with non-democratic power distribution. Assuming that deliberation and democracy are conceptually and empirically distinct, the authors define deliberative authoritarianism as 'a form of rule in which powers of decision are concentrated, but power holders enable communicative contexts that generate influence (responsiveness to claims and reasons) among the participants' (He \& Warren, 2011, pp. 273-274). The democratic value of such initiatives is questionable (Tong \& $\mathrm{He}$, 2018), but it is argued that governments tend to ensure somewhat workable mechanisms of deliberation (He \& Wagenaar, 2018).

While most authoritarian deliberation research is concentrated on state-created (invited) public spaces, less attention is given to non-institutionalized, invented or semi-invented spaces, like the social media (Jiang, 2010; Medaglia \& Zhu, 2017), or news websites comment sections (Toepfl \& Litvinenko, 2018), which are central to our research. What can be expected from such spaces in terms of deliberation? Here we propose several scenarios to be checked.

The first one is that comment sections are a mere reverberation of the governmental discourse to legitimize propaganda by 'public opinion', through various astroturfing techniques (Han, 2015) and messages moderation by the media outlets (Toepfl \& Litvinenko, 2018). The citizens with opposite views may refrain from engaging into such discussions due to self-censorship, fear and similar reasons. However, and this is the second scenario, a sort of free polarized discussion may also be of practical use for incumbents. As shown by Chen and Xu (2017), dictators may use public communication either to get feedback on policies, or to prevent collective actions by making citizens divide on policies and blame each other, not the government. In the third scenario we may expect to find 'democratic enclaves' (Gilley, 2010) - autonomous spaces that can be used by opposition activists and like-minded people to discuss politics, but their scale is too small to pose a challenge to regime stability. Although they have some democratization potential, the recent trends suggest such spaces rather contribute to the regime resilience (Kabanov \& Romanov, 2017).

We argue that all three scenarios eventually lead to regime strengthening. But the question of their deliberation quality, in terms of discourse outcomes and dominant positions, remains open. We hypothesize that in the first and third cases we are more likely to view homogeneous discourses with dominance of pro- and anti-government positions accordingly. The second case would probably allow more polarization and heterogeneity.

Due to the media fragmentation, we further hypothesize that such outcomes differ across the outlets, depending on their relationship with the government and degree of loyalty. The scenarios we outline might probably shift from the dominance of pro-government discourse to more polarized views and finally to antigovernment discourses. This tendency can be further reinforced by the 'like-minded enclave' effect (Strandberg et al., 2019) when people seek like-minded people to support their viewpoint.

The empirical research of such regime-dependent peculiarities is distorted by the general trends in delibera- 
tion and media consumption. First, it is usually observed that such news comment sections lack civility, respect and deliberation whatsoever (Zamith \& Lewis, 2014). Secondly, a variety of deliberation outcomes can be explained not only by the political orientation of the outlet, but also by the design of the comment section (Aragón, Gómez, \& Kaltenbrunner, 2017; Rowe, 2015). These limitations should be taken into consideration when interpreting the results.

\section{Research Design and Method}

\subsection{Case Study, Sample and Research Questions}

The case study for the research is based on analyzing five online discussions among Russian citizens on just one issue of the Russian anti-sanctions policy, namely, the social consequences of the government decision to destroy the embargoed food imported from the West. The decision to seize western food was taken in August 2015 in a form of the presidential decree, provoking public debates on its efficiency, morality and rationality. Several epetitions were cast to ban food destruction, including the one on the Change.org where it was signed by over 500 thousand people (https://goo.gl/FaSEDe). The issue was discussed very widely across the Russian online media.

The choice of these online debates was determined by the following factors. Firstly, there was a need to limit the coding sample with some 500 posted comments which was realistic to process due to the complexity of content coding, including the availability of trained coders and a need to cross-check the coding results. It was assumed that five discussions containing about 100 comments each would be feasible to code and analyze. From the previous research, we knew that large num- bers of comments do not necessarily improve deliberative quality, whereas several dozens of comments could be sufficient to capture the discussion essence. Secondly, as Russia does not have its official national or local eDemocracy or e-Participation platforms designed specifically to engage citizens in deliberation practices, we focused on choosing among the prominent national media that were actively reporting on food destruction when it started in August 2015 and thus attracting attention of wide audience within Russia. Typically, these were popular television channels that aired graphic video reports showing how the seized food was destroyed by bulldozers and incinerated (which was a very unusual experience to see for many Russian viewers). Thirdly, the intention was to choose a diverse set of media that would include both television and newspapers, both Russian and international, both clearly pro-government and clearly independent. And, fourthly, we wanted to ensure that the discussions themselves are not explicitly dependent on or influenced by their media hosts and, therefore, undertook a preliminary review of the previously hosted discussions to be sure that there was no visible evidence of such influence-on the contrary, there were many negative comments made by visitors in relation to authorities and their policies despite being hosted by the government-owned media; making such distinction was essential for this research.

The chosen discussions and respective media hosts are listed in Table 1.

The sample includes two national clearly progovernment television channels that had active comment sections (national coverage was important for greater outreach) and were quick to report about food destruction; namely: the Russia Today (a Russianlanguage service) and the NTV. The selection of these

Table 1. List of media hosts.

\begin{tabular}{|c|c|c|c|c|}
\hline Media hosts & Media type & Seed material / Lead article & $\begin{array}{l}\text { Number of posted } \\
\text { comments }\end{array}$ & Date of access \\
\hline $\begin{array}{l}\text { Change.org e-petition } \\
\text { website }\end{array}$ & $\begin{array}{l}\text { International, } \\
\text { independent }\end{array}$ & $\begin{array}{l}\text { Don'tCrashFood Update: We } \\
\text { will achieve our goal! Preparing } \\
\text { a conference (Savelyeva, 2015) }\end{array}$ & 76 & 30 August 2015 \\
\hline $\begin{array}{l}\text { Business Gazette Vzglayd } \\
\text { www.vz.ru }\end{array}$ & $\begin{array}{l}\text { Russian, pro- } \\
\text { government }\end{array}$ & $\begin{array}{l}\text { Polish Minister writes to Putin } \\
\text { calling food destruction a sin } \\
\text { (Vzglayd Business Gazette, 2015) }\end{array}$ & 161 & 7 August 2015 \\
\hline $\begin{array}{l}\text { Russia Today TV channel } \\
\text { www.rt.com }\end{array}$ & $\begin{array}{l}\text { Russian } \\
\text { government- } \\
\text { owned }\end{array}$ & $\begin{array}{l}\text { Dmitry Peskov's (President Putin's } \\
\text { press representative) comments } \\
\text { on the reaction following the } \\
\text { destruction of embargoed food } \\
\text { (Russia Today TV, 2015) }\end{array}$ & 34 & 5 August 2015 \\
\hline $\begin{array}{l}\text { Gamers' Playground Forum } \\
\text { www.PlayGround.ru }\end{array}$ & $\begin{array}{l}\text { Russian, } \\
\text { independent }\end{array}$ & $\begin{array}{l}\text { Destruction of embargoed food } \\
\text { (Gamers' Playground Forum, 2015) }\end{array}$ & 74 & 8 August 2015 \\
\hline $\begin{array}{l}\text { NTV TV } \\
\text { www.ntv.ru }\end{array}$ & $\begin{array}{l}\text { Russian, } \\
\text { government- } \\
\text { owned }\end{array}$ & $\begin{array}{l}\text { Tons of cheese and tomato are } \\
\text { destroyed with the help special } \\
\text { machinery (NTV, 2015) }\end{array}$ & 160 & 6 August 2015 \\
\hline
\end{tabular}


specific channels was also justified by the fact that Russia Today is a global broadcaster. In addition to these strongly pro-government television channels, one online newspaper the Vzglayd was added to the sample as a nominally business-oriented non-political media outlet. While the newspaper positions itself as an online edition for business people, its discussion forum is popular with casual visitors as well. The newspaper's owner is a Moscow-based social and economic research thinktank closely linked to the government (but not explicitly government-owned) and advocates for the government policy agenda. The remaining two media were chosen among those resources that are clearly independent from the government influence and control. One was a popular Russian-language version of the Change.org epetition portal which allows its users to discuss the submitted petitions, including a petition to stop destructing food which collected almost half-a-million supporters; hence, it was logical to include this media into the coding sample. The fifth chosen online discussion took place on the website, most popular among the Russian gamersthe Playground (in fact, a gaming server with over two million of registered users). Its advantage was that it differed from others being politically neutral (hosted by the Internet provider the RopNet).

When composing the coding sample, we were well aware about its limitations understanding that there could have been other candidates to consider as well. However, the existing scholarship on computermediated deliberation does not provide any conclusive guidance on how to compose such samples, especially in the hybrid political context and in view of the unclear link between the media host and deliberation itself. As Sandfort and Quick (2017, p. 1) note, 'no single dimension explains success or failure; the results of deliberation arise through a complex mixing of contextual and design features'. Apart from the above-mentioned selection factors, we intentionally chose to a certain extent random sample as an instant snap-shot of a far wider and deeper public debate that was unfolding on the Russian Internet. At the same time, we did not seek to construct a representative sample in a traditional sociological sense, assuming that was impossible methodologically and technically. Furthermore, we did not attempt to measure public opinion, as surveys do, but instead to measure deliberation quality and outcome by revealing the discursively and intersubjectively constructed attitudes towards food destruction at a certain time and on the certain media through 'Yes' and 'No' positions in a Habermasian tradition, as stated above. The aim was to investigate how practical reasoning was discursively applied by participants to advance particular morally and ethically justified (via claims to validity) positions (contrary to distilling public opinion that does not require social interaction among subjects).

The research aimed at accomplishing two interrelated objectives: (1) to test a proposed deliberation metrics (standard) for examining casual political conversa- tions on a salient public policy issue; and (2) to understand how deliberation quality differs depending on the media hosts' political allegiances. These objectives were supported by the following seven research questions:

RQ1: Are the online debates on pro-government media less civil than those on independent media?

RQ2: Can the messages posted on discussion threads be considered both argumentative and rational?

RQ3: Do the discourses on the independent media demonstrate higher rationality and argumentation compared with those on pro-government media?

RQ4: Is interactivity driven by agreements or disagreements?

RQ5: Do disagreements lead to more 'Against' positions, while agreements generate more 'For' positions?

RQ6: Does interactivity influence position-taking'For' or 'Against'?

RQ7: Does the pro-government or independent status of the media hosting online discussion influence deliberative quality?

\subsection{Method}

As mentioned above, the research method was based on content coding to reveal the Habermasian claims to validity of normative rightness present in discussion content, i.e., in the comments posted by discussion participants (Misnikov, 2013). The revealed validated claims were further coded to describe the various parameters of discourse quality grouped into three deliberative standards: (a) interactivity, (b) civility and (c) argumentation. While argumentation and civility are well studied, interactivity has not been examined sufficiently. We generally accept the definition of interactivity given by Rafaeli and Sudweeks $(1997,1998)$ focusing on the presence of a particular topic across a certain range of comments, i.e., a certain continuity when interactivity increases with the increase of the number of posts containing references to the same topic. That is typically done among the interacting participants when they respond to one another's messages. We consider intersubjective interactivity central to deliberation quality and propose to use a term interactive deliberation to underline the conceptual and practical importance of interactivity for deliberation. It was coded through agreements or disagreements that participants applied to make their own claims to validity and validate others' claims to display support or rejection of food destruction policy in the form of 'For' and 'Against' positions. In other words, interactivity interlinks at least two messages. For example, the 
more messages are involved in one line of argumentation, the more interactive this part of discourse is. There are always other posts that are not necessarily validated through agreement-disagreement or those that deviate from the topic of food destruction; such posts were excluded from the analysis.

The interactivity standard addressed:

- Claims to normative rightness validated via direct and indirect response to other messages and to a discussion source that initiated the discussion by agreeing-disagreeing with the meaning of the message;

- Claims to normative rightness validated via direct and indirect response to other messages only;

- Containing interactively expressed disagreements revealing 'For' and 'Against' positions with regard to food destruction policy;

- Containing interactively expressed agreements revealing 'For' and 'Against' positions with regard to food destruction policy.

The argumentation standard included references to:

- Subjective conclusions, analysis, inferences, reasoning, questioning, generalizations except declarations without justification;

- Any subjective recommendations, proposals, actions;

- Any examples, cases, comparisons, events, proverbs, dates;

- Objective facts (narrative, numerical);

- Any figures (except dates).

The civility standard coded only the explicitly: (a) rude, uncivil, derogatory, personally offensive language; and (b) expressly polite and accommodating messages.

The discussions were also checked in terms of their participatory equality to ensure that these were not 'hijacked' by few dominant participants. Overall, 333 participants posted 503 messages, which means that each participant on average posted 1 or 2 messages. Also, while there were some variations across the discussions (see Table 2), these were minor meaning that the discussions were quite equal and there were no participants that dominated them.
For ethical and privacy reasons, we did not process in any way the participants' names (nicks) that were attached to their posts and never attempted to know their real names or profiles.

\section{Research Results}

\subsection{Argumentation}

As described above, coding argumentation involved revealing five deliberative parameters: reasoning, recommendations, cases, facts and figures. At least four of five posted messages contained some sort of argumentation and reasoning regardless of the media type. The overall level of argumentation is high across all the discussions. Even a small sample pertaining to the discussion hosted by the Russia Today TV channel is part of this trend. The distribution pattern of five argumentation parameters (depicted in Figure 1) reveals that making references to subjective conclusions, analysis, inferences, questioning and generalizations are by far the most common way of reasoning for all five discussions-almost every second posts contained some sort of reasoning and argumentation $(47 \%)$.

This category is followed by the mention of comparisons, cases, events ( $22 \%$ of all posted messages) and a group of posts containing recommendations, proposals, suggestions (16\%) - the middle of the argumentation pyramid. The use of objective facts (the ones that are hard to dispute-part of the Habermasian claims to validity of the second type describing the objective world) and figures as arguments were in minority $-10 \%$ and $4 \%$ accordingly.

The data broken down by the host media political status do not yield any difference showing essentially the same levels and patterns (see Figure 2).

While the use of conclusions and other forms of reasoning appears to be a standard practice regardless of the media's political allegiance and affiliation, it should be noted that due to the casual character of the everyday political talk online, reasoning takes a loose form that does not assume presenting hard facts and justification for each instance of argumentation every time the post is written. This is a rather typical way of the casual opinion expression and argumentation based on some unproven facts or events, interpreted in a partic-

Table 2. Distribution of participants by posted comments.

\begin{tabular}{lccccc}
\hline Discussion & $\begin{array}{c}\mathbf{1} \\
\text { Comment }\end{array}$ & $\begin{array}{c}\mathbf{2 - 4} \\
\text { Comments }\end{array}$ & $\begin{array}{c}\mathbf{5 - 9} \\
\text { Comments }\end{array}$ & $\begin{array}{c}\mathbf{1 0 +} \\
\text { Comments }\end{array}$ & $\begin{array}{c}\text { Average number of comments } \\
\text { per participants }\end{array}$ \\
\hline Gamers Playground forum & $76 \%$ & $16 \%$ & $8 \%$ & $3 \%$ & 2 \\
\hline RT TV channel & $86 \%$ & $14 \%$ & $0 \%$ & $0 \%$ & 1 \\
\hline NTV channel & $86 \%$ & $14 \%$ & $0 \%$ & $0 \%$ & 1 \\
\hline Business Gazette Vzglyad & $64 \%$ & $30 \%$ & $2 \%$ & $2 \%$ & 2 \\
\hline Change.org & $81 \%$ & $18 \%$ & $0 \%$ & $0 \%$ & 1 \\
\hline
\end{tabular}




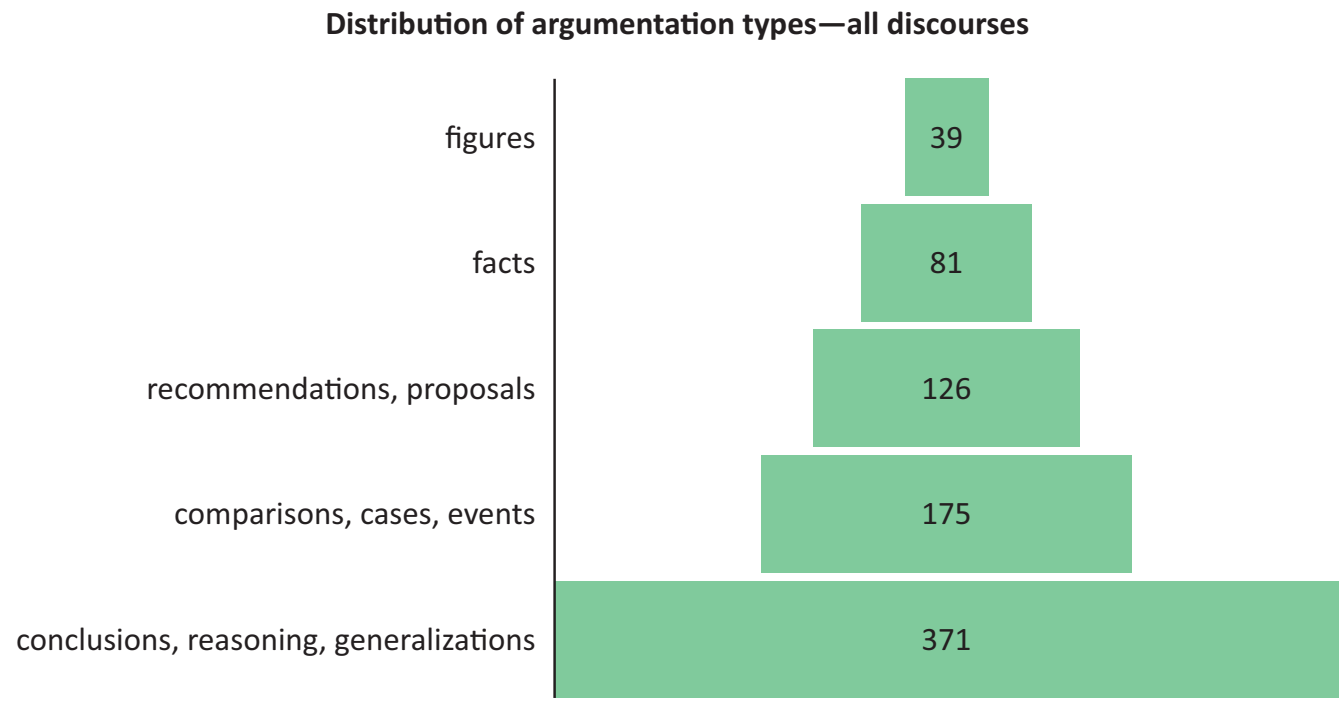

Figure 1. Distribution of argumentation type.

Argumentation on pro-government media

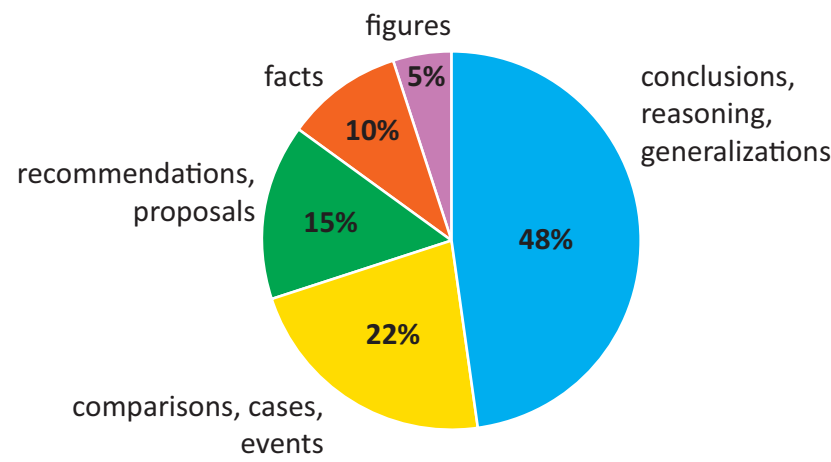

Argumentation on independent media

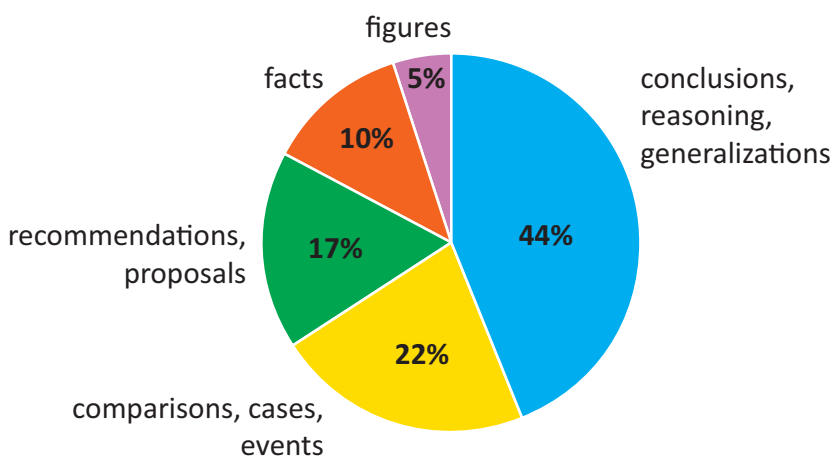

Figure 2. Use of argumentation on pro-government and independent media.

ular way-sort of a 'light' reasoning with references to common assumptions that are believed by the author to be shared by many. This is in effect a form of an argument. For example, the post says that 'smuggling with the contraband into Russia as a way of tax avoidance is not a sin, while the destruction of such contraband is a sin...' (Business Gazette Vzglayd, 2015). On the surface, this utterance looks like a mere statement not supported by specific evidence. Yet this is actually a (rhetorical) question asking the reader to contemplate about morality of food destruction; that is, whether this is sinful or not? The argument draws on a comparison with a common background knowledge in Russia, presumably shared by many, that if smuggling food into Russia to avoid paying taxes is not considered a sin (although no evidence offered to support this claim about smuggling as something 'normal' and certainly not a sin), then why its destruction should be sinful? Comparing with something commonly known is the argument deployed by the participant to convince others that destroying food is 'normal'. Yet others disagree claiming that even the contraband can be re-sold or utilized in other less dramatic ways, especially food. This kind of reasoning is ubiquitous across the discussion. Sometimes such conclusions are supported by recommendations and comparisons or references to other cases to make the argument stronger. Use of proven facts is not widespread. However, it is hard to imagine a debate among ordinary people where each participant presents facts. That does not make discussion irrational or unreasoned, since it is the meaning and interaction that matter in both moral and pragmatic discourses.

Two conclusions one might make based on the results of coding argumentation. One is that the presence of any type of reasoning does not constitute a deliberative feature of a special democratic significance. On the contrary, it is likely a standard behavior in an online debate among lay people who are interested in discussing politics in a public manner. The other finding is that such argumentation is inherent in this type of debates.

\subsection{Civility}

Civility was coded to reveal both the expressly civil, polite posts and those that are explicitly uncivil-rude, derogatory, offensive, highly personal. However, the coding re- 
sults did not show any significant number of the visibly polite posts. In contrast, as Figure 3 demonstrates, uncivil posts were common on pro-government media (25\%), particularly on the NTV channel (30\%). Discussions on the independent media were more civil, with just one in ten posts being uncivil. The higher negative emotion (typically the personally addressed messages with little substance) might be indicative of contentious debates on the state-controlled media that attract more diverse audience than on independent media which are more likely to attract like-minded participants critical of the food destruction policy.

\subsection{Interactivity}

Interactivity was coded to show how many claims to normative rightness were validated (as a percentage of all posted messages); how many of them were interactive either via agreement or disagreement; and which of these supported and rejected the policy of food destruction (see Figures 4, 5 and 6).

The overall level of deliberative interactivity (Figure 4), measured as claim validation, is between $57 \%$ on independent media and $77 \%$ on pro-government, with the level of validation reaching as much as $88 \%$ on the Russian Today TV channel and as low as $47 \%$ on the Gamers' Forum. The higher interactivity of the latter

\section{Civility on pro-government media}

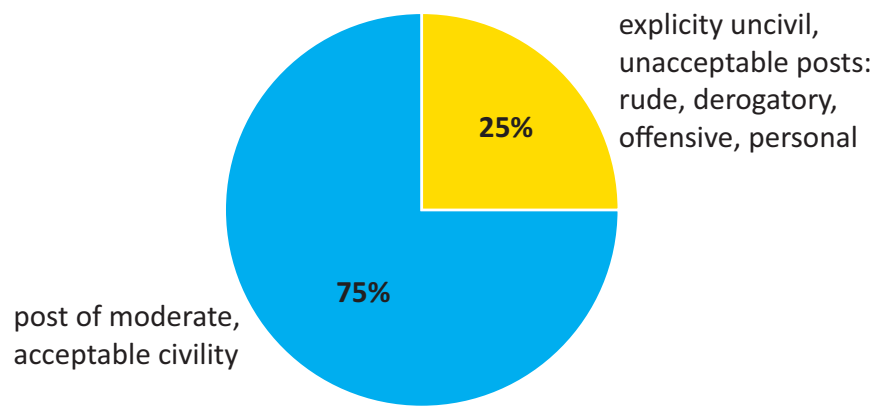

Figure 3. Civility on pro-government and independent media.

Validation on pro-government media

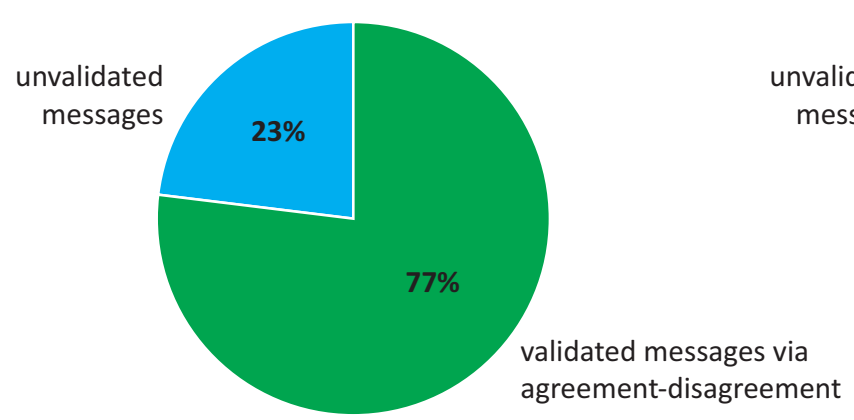

might be an effect of the more contentious type of debate there when disparities in views lead to more interaction. However, that link needs further examination and additional evidence to prove or disprove it. In any case, both cases demonstrate a rather high level of reciprocity among participants for a casual talk discussing just one topic of food destruction (other topic were not coded). Larger differences emerge when it comes to the use of agreements and disagreements when validating the claims made (see Figure 5). For example, interactive disagreements are noticeably higher among the statecontrolled media ranging from $68 \%$ in the case of the NTV channel to $39 \%$ on the website of the Vzglyad (the average is $56 \%$ ). While this difference is substantial, it is still smaller than the level of disagreement on the independent media-29\% (18\% for the discussion on the Change.org and $24 \%$ on the Gamers' Forum). In a similar vein, the use of deliberative agreements is even stronger on the independent media- $82 \%$ on the Change.org and $76 \%$ on the Gamers' Forum against $41 \%$ on Russian Today and $32 \%$ on the NTV. It is not clear what causes such differentiation. Agreements and disagreements are just discursive instruments to claim something or validate other claims to reveal a position or an opinion. Technically speaking, it does not matter whether the rejection of food destruction is materialized through agreeing or disagreeing. The process of coding agreements and dis-

\section{Civility on independent media}

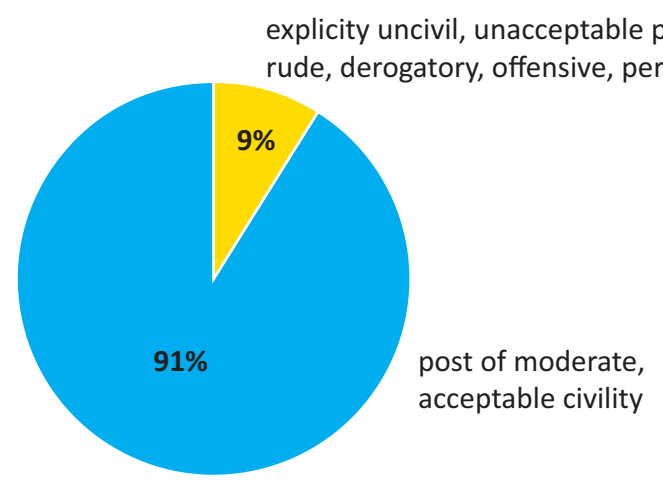

Figure 4. Validation of claims to normative rightness on pro-government and independent media. 
Interactive agreements and disagreements on pro-government media

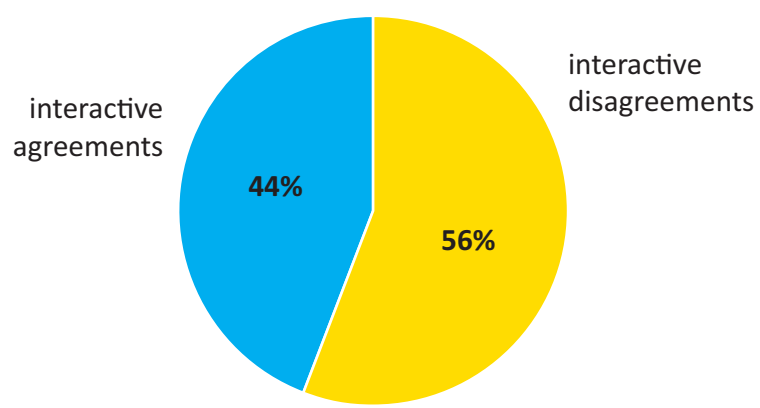

Interactive agreements and disagreements on independent media

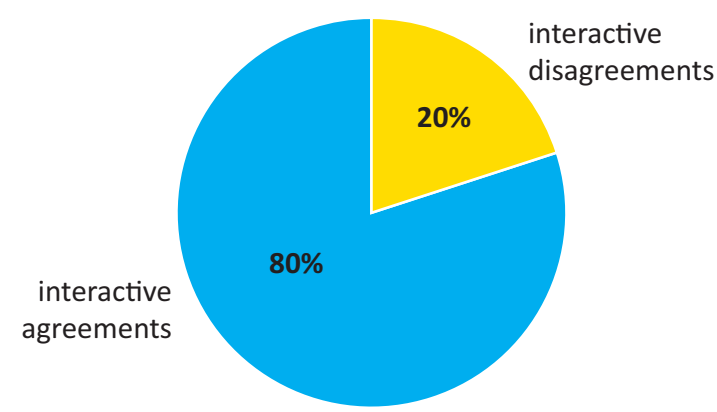

Figure 5. Interactive agreements and disagreements on pro-government and independent media.

agreements was linked to the claim making and validation process which allows focusing only on the most recent acts of agreement-disagreement related validations. More research would be needed to provide a plausible explanation why the pro-government media demonstrate more contentious type of public discourse compared with the independent media. We can hypothesize, however, drawing on other research, that on the surface it looks like a manifestation of the 'like-minded enclave' (Strandberg et al., 2019) or the impact of the homophily factor prompting the emergence of the like-minded solidarities (Mutz, 2006) on the independent media among those who do not trust the pro-government media and choose alternative places to express disapproval of the food destruction policy. Naturally, the level of disagreement among the like-minded people is expected to be lower on such a morally loaded issue.

Figure 6 reveals the discursively formed intersubjective solidarities of discussants differing in their attitude towards the policy of food destruction. There is a strong correlation-although not necessarily a causeeffect relationship-between the media political allegiances and the attitude to food destruction. Participants on the independent media reject overwhelmingly food destruction (for in five are against), while the balance on the pro-government media is more muted with roughly

\section{Attitude towards food destruction policy} in pro-government media

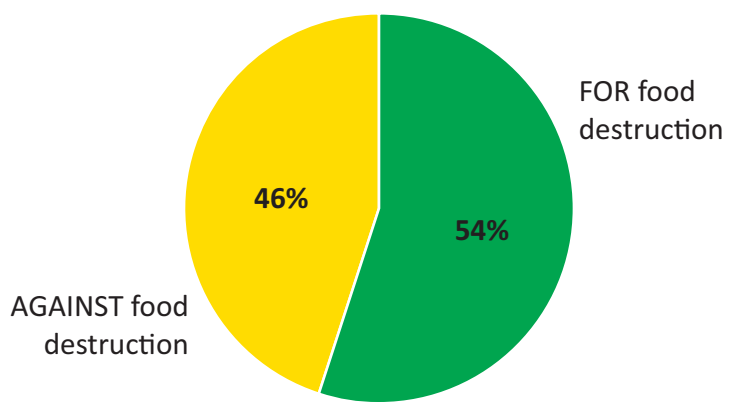

one half being in favor with the other half against. It seems that while the independent media may be seen morally superior in its protest against food destruction, it also signals about the 'like-minded enclave' syndrome. On the other hand, the pro-government media demonstrate more diverse debate in supporting the policy of food destruction.

\section{Discussion}

We argue that our study contributes to the existing literature on authoritarian deliberation in several ways. First, the research echoes the assumption (He \& Warren, 2011) that deliberation and democracy are conceptually and empirically discernable phenomena: the former may exist across different political regimes and institutional settings. The lack of political pluralism should not be simply considered a counter-indication for deliberation, rather an important object of study within deliberation research theories and methods, previously designed for democracies only.

Secondly, deliberation in autocracies is not limited to the government-created and -led domains, designed to support decision-making and facilitate information gathering (He \& Warren, 2011). Our research shows that deliberative practices in non-competitive contexts may ex-

\section{Attitude towards food destruction policy on independent media}

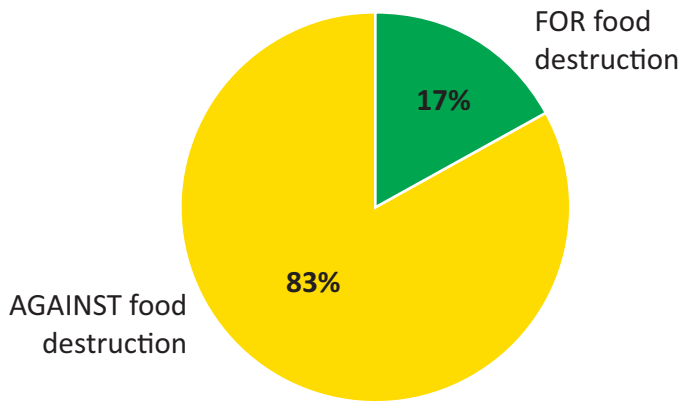

Figure 6. Intersubjective solidarities 'For' and 'Against' food destruction on pro-government and independent media. 
ist in 'semi-invented' spaces, although patterns and quality of deliberation vary, depending on the political affiliation of the outlets. That speaks for expanding the authoritarian deliberation framework to a larger set of online platforms. The methodology proposed in this study might be a useful tool for such analysis.

At the same time, one should not overestimate the potential of such deliberation to influence decisionmaking or contribute to democratization. Rather it provides several additional mechanisms of the regime resilience. Out of the three scenarios mentioned in Section 2.2, our research reveals the second and the third one. Discussions on the pro-government media do not hold exclusively the pro-government discourse, but equal proportions of those supporting and opposing food destruction. Rather than being a tool of direct propaganda, they represent a space for disagreement and polarization, intensified by higher rated uncivility and offensive utterances (RQ1).

The clear dominance of the anti-policy discourse in the independent media exemplifies the 'democratic enclave' (Gilley, 2010) scenario, but can also present the 'like-minded enclave' effect (Strandberg et al., 2019). Such 'enclaves' are unlikely to become drivers of democratization, or at least, 'schools' of deliberative democracy. Even though there is a clear link between anti-policy discourse in the independent media and a strong focus on interactive agreements, there is no visible connection between the deliberation quality and the media's political stance (RQ7).

Hence, both scenarios help the authoritarian regime to be stable: while polarization helps autocrats to amortize the negative effects of an unpopular policy (Chen $\& X u, 2017)$, the 'enclaves' channel the discontent in a 'safe' manner.

However, other tested criteria of deliberation are quite equally present across platforms (RQ3). As for rationality and argumentation (RQ1), the coding results reveal that as many as four of five messages contain some sort of reasoning. The use of objective facts is minimal across the media. The casual format of argumentation should not be confused with the logic typical to expert talks, but it is also accepted by other participants, and the level of argumentation in various media seems almost identical.

The available evidence suggests that neither agreement nor disagreement determine how interactive the discussion is (RQ4)-with roughly the same level of deliberative interactivity, the level of agreements and disagreements vary vastly across the media. Nor is there evidence to suggest that there is a clear pattern pointing at the existence of a link between agreeing-disagreeing and position-taking. The respective parameters differ greatly (RQ5). Finally, no relationship has been discerned between interactivity and how often discourse participants take a position 'For' or 'Against' food destruction policy (RQ6). Generally, the overall interactivity has not demonstrated high variability.

\section{Conclusion}

Our findings suggest that authoritarian deliberation is a promising research domain within a general deliberation research, which furthermore contributes to our understanding of the contemporary nature of non-democratic rule (Gerschewski, 2013). At the same time, the shift from invented to (semi-)invited spaces raises some theoretical and methodological complications. First, it is hard to reveal the influence of authoritarian incumbents on the process and outcomes of deliberation, as this effect is distorted by private actors: media owners and citizens themselves. Secondly, while the effect of governmentled discussions on policy outcomes can be measured, it is hard to trace the influence of informal discourse on policy change. As our case suggested, such deliberation occurred after the decision had already been taken, and even if it had been held before, the government would have had enormous discretion of taking those opinions into account. Thirdly, it might be problematic to estimate the sample needed for assessing the deliberative potential of the Internet: our 5 outlets represent only a minor segment of the online public discourse, and it is unclear whether it is enough to draw meaningful conclusions. Finally, as deliberation is a very complex concept, more deliberation criteria should be taken into account. We hope that this research can become a step towards resolution of these problems and developing practical solutions for deliberation to become meaningful regardless of the political regime.

\section{Acknowledgments}

The research was supported by the Russian Science Foundation, grant № 18-18-00360 'E-participation as Politics and Public Policy Dynamic Factor'.

\section{Conflict of Interests}

The authors declare no conflict of interests.

\section{References}

Aragón, P., Gómez, V., \& Kaltenbrunner, A. (2017). Detecting platform effects in online discussions. Policy \& Internet, 9(4), 420-443.

Åström, J., Karlsson, M., Linde, J., \& Pirannejad, A. (2012). Understanding the rise of e-participation in non-democracies: Domestic and international factors. Government Information Quarterly, 29(2), 142-150.

Bohman, J. (1996). Public deliberation: Pluralism, complexity, and democracy. Cambridge, MA: MIT Press.

Bohman, J., \& Rehg, W. (Eds.). (1997). Deliberative democracy: Essays on reason and politics. Cambridge, MA: MIT Press.

Chen, J., \& Xu, Y. (2017). Why do authoritarian regimes allow citizens to voice opinions publicly? The Journal 
of Politics, 79(3), 792-803.

Coleman, S. (2017). Can the Internet strengthen democracy? Cambridge, Malden, MA: Polity Press.

Dryzek, J. S. (2000). Deliberative democracy and beyond: Liberals, critics, contestations. Oxford and New York, NY: Oxford University Press.

Elster, J. (Ed.). (1998). Deliberative democracy (Vol. 1). Cambridge: Cambridge University Press.

Friess, D., \& Eilders, C. (2015). A systematic review of online deliberation research. Policy \& Internet, 7(3), 319-339.

Gamers' Playground Forum. (2015). Destruction of embargoed food. Playground. Retrieved from https:// forums.playground.ru/talk/society/unichtozhenie_ sanktsionnyh_produktov_vashe_mnenie-874249

Gastil, J. (2008). Political communication and deliberation. Los Angeles, CA, London, New Delhi and Singapore: Sage.

Gel'man, V. (2015). Authoritarian Russia: Analyzing postsoviet regime changes. Pittsburg, CA: University of Pittsburgh Press.

Gerschewski, J. (2013). The three pillars of stability: Legitimation, repression, and co-optation in autocratic regimes. Democratization, 20(1), 13-38.

Gilley, B. (2010). Democratic enclaves in authoritarian regimes. Democratization, 17(3), 389-415.

Gunitsky, S. (2015). Corrupting the cyber-commons: Social media as a tool of autocratic stability. Perspectives on Politics, 13(1), 42-54.

Gutmann, A., \& Thompson, D. (2004). Why deliberative democracy? Princeton, NJ: Princeton University Press.

Habermas, J. (1984). The theory of communicative action. Vol. 1: Reason and the rationalization of society. Boston, MA: Beacon.

Habermas, J. (1987). The philosophical discourse of modernity. Cambridge: Polity Press.

Habermas, J. (1992a). Moral consciousness and communicative action. Cambridge: Polity Press.

Habermas, J. (1992b). Concluding remarks. In C. Calhoun (Ed.), Habermas and the public sphere (pp. 462-479). Cambridge, MA: The MIT Press.

Habermas, J. (2006). Political communication in media society: Does democracy still enjoy an epistemic dimension? The impact of normative theory on empirical research. Communication Pheory, 16(4), 411-426.

Han, R. (2015). Manufacturing consent in cyberspace: China's 'fifty-cent army'. Journal of Current Chinese Affairs, 44(8), 105-134.

He, B., Tang, B., \& Tamura, T. (2018). Deliberative democracy in East Asia: Japan and China. In A. Bächtiger, J. S. Dryzek, J. Mansbridge \& M. E. Warren (Eds.), The Oxford handbook of deliberative democracy (pp. 791-804). Oxford: Oxford University Press.

He, B., \& Wagenaar, H. (2018). Authoritarian deliberation revisited. Japanese Journal of Political Science, 19(4), 622-629.
He, B., \& Warren, M. E. (2011). Authoritarian deliberation: The deliberative turn in Chinese political development. Perspectives on Politics, 9(2), 269-289.

Huang, H., Boranbay-Akan, S., \& Huang, L. (2019). Media, protest diffusion, and authoritarian resilience. Political Science Research and Methods, 7(1), 23-42.

Jiang, M. (2010). Spaces of authoritarian deliberation: Online public deliberation in China. In E. Leib \& B. He (Eds.), The search for deliberative democracy in China (2nd ed., pp. 261-287). New York, NY: Palgrave

Jonsson, M. E., \& Åström, J. (2014). The challenges for online deliberation research: A literature review. International Journal of E-Politics (IJEP), 5(1), $1-15$.

Kabanov, Y., \& Romanov, B. (2017). Interaction between the internet and the political regime: An empirical study (1995-2015). In D. Alexandrov, A. Boukhanovsky, A. Chugunov, Y. Kabanov, \& O. Koltsova (Eds.), Digital transformation and global society: Second international conference, DTGS 2017, St. Petersburg, Russia, June 21-23, 2017, revised selected papers (pp. 282-291). Cham: Springer.

Kersting, N. (2013). Online participation: From 'invited' to 'invented' spaces. International Journal of Electronic Governance, 6(4), 270-280.

Medaglia, R., \& Yang, Y. (2017). Online public deliberation in China: Evolution of interaction patterns and network homophily in the Tianya discussion forum. Information, Communication \& Society, 20(5), 733-753.

Medaglia, R., \& Zhu, D. (2017). Public deliberation on government-managed social media: A study on Weibo users in China. Government Information Quarterly, 34(3), 533-544.

Misnikov, Y. (2013). You say 'yes', I say 'no': Capturing and measuring 'public opinion' through citizens' conversation online (on the Russian-language livejornal blogging platform). In M. A. Wimmer, E. Tambouris, \& A. Macintosh (Eds.), Electronic participation: 5th IFIP WG 8.5 international conference, ePart 2013, Koblenz, Germany, September 17-19, 2013. Proceedings (pp. 134-146). Berlin: Springer.

Mutz, D. C. (2006). Hearing the other side: Deliberative versus participatory democracy. Cambridge: Cambridge University Press.

NTV. (2015). Tons of cheese and tomato are destroyed with the help special machinery. NTV. Retrieved from https://www.ntv.ru/novosti/1457496

Rafaeli, S., \& Sudweeks, F. (1997). Networked interactivity. Journal of Computer-Mediated Communication, 2(4), JCMC243.

Rafaeli, S., \& Sudweeks, F. (1998). Interactivity on the nets. In F. Sudweeks, M. L. McLaughlin, \& S. Rafaeli (Eds.), Network and netplay: Virtual groups on the internet (pp. 173-189). Menlo Park, CA, Cambridge, MA and London: AAA Press and MIT Press.

Romano, G. C. (2018). A critical reappraisal of resident 
participation in China and France: 'Authoritarian deliberation' goes global? Japanese Journal of Political Science, 19(4), 709-722.

Rowe, I. (2015). Deliberation 2.0: Comparing the deliberative quality of online news user comments across platforms. Journal of Broadcasting \& Electronic Media, 59(4), 539-555.

Russia Today TV. (2015). Dmitry Peskov's (President Putin's press representative) comments on the reaction following the destruction of embargoed food. Retrieved from https://russian.rt.com/article/ 107403

Sandfort, J., \& Quick, K. (2017). Deliberative technology: A holistic lens for interpreting resources and dynamics in deliberation. Journal of Public Deliberation, 13(1), 1-32.

Savelyeva, S. (2015). Don't crash food update: We will achieve our goal! Preparing a conference. Change.org. Retrieved from https://bit.ly/2S7XrwE

Schedler, A. (2009). The new institutionalism in the study of authoritarian regimes. Totalitarismus und Demokratie, 6(2), 323-340.

Soldatov, A., \& Borogan, I. (2015). The red web: The struggle between Russia's digital dictators and the new online revolutionaries. New York, NY: PublicAffairs.

Stafford, E. (2017). Stop the presses! Media freedom in authoritarian regimes: A case study of Ben Ali's Tunisia. The Journal of the Middle East and Africa, 8(4), 353-381.

Stier, S. (2015). Democracy, autocracy and the news: The impact of regime type on media freedom. Democratization, 22(7), 1273-1295.
Strandberg, K., Himmelroos, S., \& Grönlund, K. (2019). Do discussions in like-minded groups necessarily lead to more extreme opinions? Deliberative democracy and group polarization. International Political Science Review, 40(1), 41-57.

Sunstein, C. (2009). Going to extremes: How like minds unite and divide. Oxford: Oxford University Press.

Toepfl, F. (2018). Innovating consultative authoritarianism: Internet votes as a novel digital tool to stabilize non-democratic rule in Russia. New Media \& Society, 20(3), 956-972.

Toepfl, F., \& Litvinenko, A. (2018). Transferring control from the backend to the frontend: A comparison of the discourse architectures of comment sections on news websites across the post-Soviet world. New Media \& Society, 20(8), 2844-2861.

Tong, D., \& He, B. (2018). How democratic are Chinese grassroots deliberations? An empirical study of 393 deliberation experiments in China. Japanese Journal of Political Science, 19(4), 630-642.

Wright, S. (2012). From 'third place' to 'third space': Everyday political talk in non-political online spaces. Javnost-The Public, 19(3), 5-20.

Vzglayd Business Gazette. (2015). Polish Minister writes to Putin calling food destruction a sin. Vzglayd Business Gazette. Retrieved from https://vz.ru/news/ 2015/8/7/760122.html

Zamith, R., \& Lewis, S. C. (2014). From public spaces to public sphere: Rethinking systems for reader comments on online news sites. Digital Journalism, 2(4), 558-574.

\section{About the Authors}

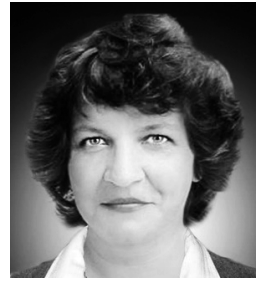

Olga Filatova is an Associate Professor at the Department of PR in Politics and Public Administration, St. Petersburg State University. She holds PhD in Philosophy (1994) and has authored more than 200 publications, including textbooks on PR, social and political research. She is a laureate of several professional contests in Public Relations: "White Wing" and PROBA-IPRA GWA. Her main research interests include strategic and political communication, as well as ICT in politics.

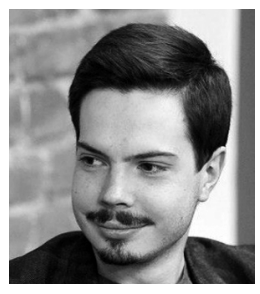

Yury Kabanov is a Senior Lecturer at the Department of Political Science, the Higher School of Economics (St. Petersburg), as well as a Researcher at the eGovernment Center of ITMO University. He has more than 20 academic publications on e-government and e-participation research. His current scientific interests include the Internet and politics, with the special emphasis on comparative authoritarianism and governance issues.

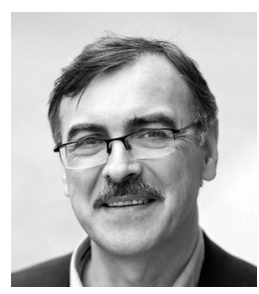

Yuri Misnikov holds a PhD degree in New Media and Communications from the University of Leeds. He is a qualified expert in e-democracy and e-participation with 20 years of international professional experience, including a position of eGovernance Regional Policy Advisor for Europe and the CIS with the United Nations Development Programme. Over the past several years he has actively participated in the EU studies aimed at harmonizing digital markets in the Eastern Partnership countries. He currently works as a Researcher at the eGovernment Center of ITMO University, focusing on online deliberation practices across the media. 